\title{
YOLO - Your Own Living Object
}

\author{
Patrícia Alves-Oliveira \\ Iscte - Instituto Universitário de Lisboa, INESC-ID, \\ Cornell University \\ Lisbon, Portugal, and Ithaca, NY, USA \\ patricia_alves_oliveira@iscte-iul.pt \\ Ana Paiva \\ Instituto Superior Técnico-UL, INESC-ID \\ Lisbon, Portugal \\ ana.paiva@inesc-id.pt
}

\begin{abstract}
Creativity is at the core of what it means to be human. It is an intrinsic ability that we all have and influences our well-being self-expression throughout life. However, a decline in creativity abilities occurs in children around the age of 7 years old. Our work aims to contribute to a re-balance of creative levels using social robots. In this video, we describe YOLO, an autonomous robotic toy for children that fosters their creativity during play. This robot is envisioned to be used as a character during storytelling, promoting creative story-lines that might not emerge otherwise.
\end{abstract}

\section{ACM Reference Format:}

Patrícia Alves-Oliveira, Patrícia Arriaga, Ana Paiva, and Guy Hoffman. 2020. YOLO - Your Own Living Object. In Companion of the 2020 ACM/IEEE International Conference on Human-Robot Interaction (HRI '20 Companion), March 23-26, 2020, Cambridge, United Kingdom.. ACM, New York, NY, USA, 1 page. https://doi.org/10.1145/3371382.3378395

\section{INTRODUCTION}

Creativity is defined as the ability to produce something that is both novel and useful within a social context [1]. It is an important ability to have, as it promotes healthy development in which competencies of problem solving and thinking outside of the box are nurtured, stimulated, and rewarded in later life stages [2]. Creativity during childhood appears as a predictor of creativity levels in adulthood [3]. Therefore, it is crucial to stimulate this ability in the early stages of life. However, creativity levels fluctuate during the lifespan and suffer a first major decline around the age of 7 years old, in a phenomena named the "creativity crisis" [4]. Notwithstanding, creativity can be developed with proper training and interventions for creativity have been validated showing varying degrees of effectiveness [5]. This work aims to contribute to the development of robots that can be used to empower creativity. Therefore, we have designed, fabricated, and tested YOLO ("Your Own Living Object"), a robot meant to boost creativity in children.

Permission to make digital or hard copies of part or all of this work for personal or classroom use is granted without fee provided that copies are not made or distributed for profit or commercial advantage and that copies bear this notice and the full citation on the first page. Copyrights for third-party components of this work must be honored. For all other uses, contact the owner/author(s).

HRI '20 Companion, March 23-26, 2020, Cambridge, United Kingdom.

(c) 2020 Copyright held by the owner/author(s).

ACM ISBN 978-1-4503-7057-8/20/03.

https://doi.org/10.1145/3371382.3378395

\author{
Patrícia Arriaga \\ Iscte - Instituto Universitário de Lisboa, CIS-IUL \\ Lisbon, Portugal \\ patricia_arriaga@iscte-iul.pt
}

\author{
Guy Hoffman \\ Cornell University \\ Ithaca, NY, USA \\ hoffman@cornell.edu
}

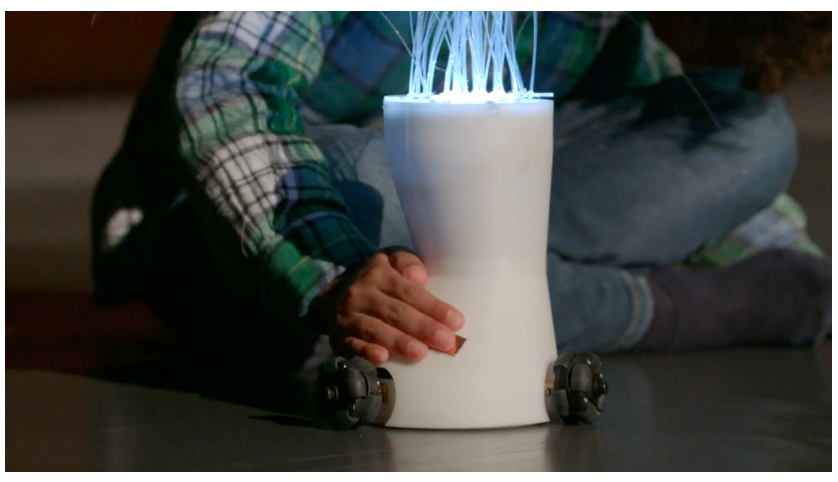

Figure 1: Child playing with YOLO.

\section{TECHNICAL OVERVIEW AND VIDEO}

Our video (https://youtu.be/e-K3J5UZ9M4) shows YOLO, a robot for children aimed at stimulating their creativity during play (see Figure 1). YOLO is a small and light-weight robotic toy that acts autonomously during children's play to develop their creativity and uses minimalistic expressive behaviors (i.e., lights and movements). It uses two techniques: (1) Mirroring is used to stimulate convergent thinking as YOLO mimics the play motions performed by children, converging on ideas for the story; (2) Contrasting is used to stimulate divergent thinking as YOLO contrasts play motions aiming for a twist in the plot. YOLO decides which technique to use according to the storytelling stage where children are, which is associated to different story timings.

\section{ACKNOWLEDGEMENTS}

This work was supported through Fundação para a Ciência e a Tecnologia (FCT). P. Alves-Oliveira acknowledges an FCT Grant, FRH/BD/110223/2015.

\section{REFERENCES}

[1] J. A. Plucker, R. A. Beghetto, and G. T. Dow, "Why isn't creativity more important to educational psychologists? potentials, pitfalls, and future directions in creativity research," Educational psychologist, vol. 39, no. 2, pp. 83-96, 2004.

[2] J. Kaufman, "Creativity as a stepping stone toward a brighter future," fournal of Intelligence, vol. 6, no. 2, pp. 1-7, 2018.

[3] S. Ayman-Nolley, "Vygotsky's perspective on the development of imagination and creativity," Creativity Research fournal, vol. 5, no. 1, pp. 77-85, 1992.

[4] K. H. Kim, "The creativity crisis: The decrease in creative thinking scores on the torrance tests of creative thinking," Creativity Research fournal, vol. 23, no. 4, pp. 285-295, 2011.

[5] G. Scott, L. E. Leritz, and M. D. Mumford, "Types of creativity training: Approaches and their effectiveness," The Journal of Creative Behavior, vol. 38, no. 3, pp. 149-179, 2004 . 